\title{
Subvertendo gênero: o lugar da não-binaridade numa análise discursiva de "blogs"
}

\author{
Subverting gender: the place of non-binarity in \\ a discursive analysis of blogs
}

\section{Patricia Mendes Lemos' ${ }^{1}$ (i) Anne Graça de Sousa Andrade² (D) Bianca Maria Lima Cardoso 3 (D)}

'Autora para correspondência. Faculdade Luciano Feijão (Sobral). Ceará, Brasil. ptmenl_78@hotmail.com 2,3Faculdade Luciano Feijão (Sobral). Ceará, Brasil. annegsa@hotmail.com, biancabrmaria@hotmail.com

RESUMO | As questões de gênero têm despontado inúmeras discussões ao longo da história nas diferentes sociedades. $\mathrm{Na}$ contemporaneidade, as diferentes designações de gênero encontradas têm provocado a necessidade premente de pesquisas aprofundadas que compreendam o fenômeno e apontem intervenções ante a sua complexidade. Na presente pesquisa traçou-se como objetivo compreender o lugar não-binário de identidade(s) de gênero a partir da análise de mídias virtuais, assim como analisar os discursos produzidos sobre esse lugar de identificação não-binária, além de apreender as dimensões políticas de representação dos discursos acerca da não-binaridade de gênero. Para tanto, utilizou-se uma metodologia de cunho qualitativo através da análise de discurso que viabilizou a apreensão de categorias teóricas das significações dos discursos acessados em blogs localizadas na plataforma Google e selecionados com o descritor "O que é não-binaridade de gênero? - blogs", blogs brasileiros e em língua portuguesa. Como resultados obtidos foram esboçadas duas categorias temáticas: a) Construção de significados de identidade não-binária: e b) (In) definição do ser não-binário. Inferiu-se da investigação considerações relevantes sobre os posicionamentos discursivos quanto aos seus significados como termos e designações identitárias, quanto ao lugar de fala dos sujeitos, e quanto a uma dimensão ético e política necessária para a convivência entre os diferentes gêneros.

PALAVRAS-CHAVE: Orientação sexual. Não Binaridade. Mídia.

\begin{abstract}
Gender issues have sparked countless discussions throughout history in different societies. In contemporary times, the different gender designations found have provoked the urgent need for in-depth research that understands the phenomenon and points out interventions due to its complexity. In the present research, the objective was to understand the non-binary place of gender identity (ies) from the analysis of virtual media, as well as to analyze the discourses produced on this place of non-binary identification, as well as to apprehend the political dimensions of representation of the discourses about gender non-binarity. To this end, a qualitative methodology was used through discourse analysis that enabled the apprehension of theoretical categories of the meanings of the discourses accessed on blogs located on the Google platform and selected with the descriptor "What is gender non-binarity? - blogs ", Brazilian and Portugueselanguage blogs. As a result, two thematic categories were outlined: a) Construction of meanings of non-binary identity: and b) (In) definition of non-binary bein. It was inferred from the research relevant considerations on the discursive positions as to their meanings as terms and identity designations, as to the place of speech of the subjects, and as to an ethical and political dimension necessary for the coexistence between the different genres.
\end{abstract}

KEYWORDS: Sexual orientation. Non-binarity. Media. 


\section{Introdução}

A discussão sobre as identidades de gênero tem se mostrado necessária e relevante por representar um movimento histórico de nossa sociedade, que ao longo de sua construção teórica acerca da temática, tendeu a privilegiar a diferença sexual entre homens e mulheres (com foco na dimensão biológica) para identificar qual o gênero pertencente a determinados grupos, realizando uma espécie de normatização. Questionar o conceito de gênero e suas diferentes identidades significa realizar uma análise de cunho social e de seus significados, pondo em xeque a identidade de feminino e masculino apresentadas à nossa compreensão.

Os papeis que representam o que é masculino ou feminino tradicionalmente, em geral se restringem a definições biológicas e/ou binárias, restritas a dois elementos de categorização, servindo a uma tipificação padronizada de identidades de gênero. Entretanto, paralelamente à tradição e à norma, outros modos de identificação e não identificação vão se disseminando em nossa cultura, pautando-se em novas configurações sociais e históricas, permitindo modos de construções subjetivas que englobem tanto as duas classes (anteriormente tidas como exclusivas), como sendo concebidas para além dessa designação binária.

A partir dos questionamentos do que seria socialmente considerado feminino ou masculino, começam a se construir relações que permeiam o entre (intervalo entre ser homem e ser mulher), apontando então para uma construção do social e identitária do sujeito transpassada por relações diversas, experiências singulares, valores assimilados nas interações com o seu contexto. O sujeito passa a se posicionar diante do que é imposto e questionável, encontrando modos outros de se identificar e se perceber em seus papéis sociais de gênero, subvertendo a lógica vigente.

Situamo-nos na Contemporaneidade ou Modernidade Alta ou Tardia (Giddens, 2002), época relacionada aos desdobramentos da lógica do funcionamento do capitalismo e declínio e fragmentação das referências e valores estabelecidos na Modernidade. Consideramos, neste estudo, o contexto da cultura ocidental, em seus novos modos de convivência, incluindo o cyberespaço. O cenário social em questão pressupõe a tentativa de homogeneização das subjetividades e ao mesmo tempo a abertura para o rompimento de racionalidades tradicionais, pela imposição e impossibilidade de negação das diferenças.

No aspecto paradoxal, característico de nossos tempos, há que se levar em conta a realidade do mundo virtual em nossas vidas. Compreendemos que, na experiência humana, ocorrem variações de realização e irrealização. O real não é diferente do possível, do irrealista, do realizável, do desejável, do utópico, do absurdo, do razoável, do custoso. Tudo isso compõe a vastidão das experiências possível. De modo que a virtualidade em si não constitui um evento positivo ou negativo, mas possui, como todo o resto, as duas dimensões (Lévy, 1996).

A relevância do estudo consiste em trazer à discussão uma temática atual e emblemática, tanto nos discursos midiáticos, que se apresentam como novos modos de criação e expressão de subjetividades, como na abordagem da não-binaridade na discussão de gêneros e seus desdobramentos sociais e políticos.

Diante dessas considerações, buscamos a investigação da temática da não-binaridade como possibilidade de desconstrução da lógica de gênero alicerçada historicamente. A relevância dessa discussão revela-se na compressão sócio-histórica dos processos de subjetivação pautados na sexualidade humana e nas expressões identitárias de gênero. A atualidade do tema em questão constitui um desafio necessário com vistas a promover espaços mais democráticos no que concerne à vivência dos papeis de gênero, em sua pluralidade e liberdade, assim como a propiciar o diálogo com as novas possibilidades de não identificação a gêneros específicos, as quais atendam às demandas de sofrimento de grupos e sujeitos alvos de uma cultura homogênea e hetero-normativa, facilitadora de práticas recorrentes de homofobia.

Objetivamos compreender o lugar não-binário de identidade(s) de gênero, através da análise dos discursos produzidos dentro das plataformas blogs de domínio público, assim como identificar definições e representações subjetivas ligadas ao termos encontrados, e apreender os modos de identificação e designação de gênero dos sujeitos que se percebem e se definem a partir da experiência de não-binaridade de gênero.

Pesquisas neste campo visam a suprir a escassez de produções científicas acerca de temas como a 
não-binaridade, tanto no campo psicológico, como em outras áreas sociais, onde a ideia de subversão da lógica binária de gênero mostra-se uma impossibilidade teórica, assim como de modo concreto na vida dos sujeitos.

No que diz respeito à fundamentação teórica acerca do assunto, adotamos as perspectivas de Foucault (1988; 2009) e Butler (2013) para explanar o lugar do corpo como performance e a apresentação de um lugar social para os sujeitos, que se afirme conjuntamente a um questionamento de papeis femininos e masculinos construídos e desconstruídos historicamente. A partir da complexidade dos autores em sua leitura das ideologias presentes no campo da sexualidade, discutiremos sobre as concepções históricas, sociais e discursivas de gêneros; pautados na constituição das relações sociais entre os sujeitos e grupos, passando pelas noções binárias e a criação de um repertório padrão de identificação delas decorrentes, até a apresentação de novos conceitos que permitam revelar as vivências plurais da diversidade de gêneros descritas e praticadas pelos sujeitos em suas interações no mundo, passando a entender gênero a partir da subversão do conceito de identidade.

Expressamos o entendimento dos discursos e das relações entre os sujeitos como constituições sociais, partindo de um pensamento crítico sobre as produções de verdade e os dispositivos de sexualidade, incorrendo na reflexão sobre como se dão as relações de saber/poder nas instituições dentro de nossa cultura aquelas que ditam os moldes das identidades sexuais e de gênero - e como os sujeitos (re)produzem suas narrativas nelas pautados, buscando compreender as repercussões disso para a construção de uma verdade social e cultural sobre as identidades em questão.

Ao abordar os processos de construção identitária, a Psicologia vai ao encontro dos discursos comumente propagados e sustentados socialmente, questionando-os, bem como investigando a forma como alguns sujeitos, de gêneros distintos da norma, vivenciam subjetivamente e dão significado às imposições da cultura, experimentando uma espécie de inadequação e processos de exclusão e negação de suas existências. A ciência psicológica cumpre a função de investigar como o sujeito assimila e se posiciona frente a essas performatividades de gênero ditas e não ditas nas mídias, realizando o enquadramento ou mesmo escapando de qualquer forma de definição, mas se afirmando e inventando espaços de pertencimento.

\section{Construções históricas, sociais e discursivas do conceito de gênero}

A concepção da noção de identidade de gênero constitui-se como uma questão permeada por debates históricos, sociais, políticos e culturais, numa forma de compreensão que considera a identificação estrita com algo que está posto como feminino ou masculino. A quebra desse panorama torna-se possível na discussão apresentada pela dimensão não-binária, não-categorizada de gênero, a qual aponta para uma não-identificação com os padrões impostos socialmente, como denota Torrão Filho (2005, p. 136): “[...] o gênero se preocupa com a consolidação de um discurso que constrói uma identidade do feminino e do masculino que encarcera homens e mulheres em seus limites, aos quais a história deve libertar".

Pensar historicamente no surgimento do conceito de gênero em seu sentido mais amplo é compreender as construções sociais e culturais de cada época que deram espaço ao surgimento das identificações, as quais inicialmente se baseavam no ser feminino e no ser masculino. Se considerarmos gênero como aquilo que se constrói como papéis sociais atribuídos aos sujeitos (para o feminino, o lugar do cuidado, da sensibilidade, da maternidade, da submissão, da vaidade; para o masculino, o trabalho, a força, a virilidade, a agressividade, etc.), necessitaremos empreender o esforço da análise histórica de como essas funções e papéis sofreram mudanças ao longo do tempo em cada cultura, e como podem ser interpretados em seu contexto de surgimento e nas metamorfoses sofridas.

A diferenciação de sexos, segundo Fonseca (2005), aparece nos estudos sociológicos e antropológicos a partir das primeiras civilizações, onde havia a atribuição de papéis em cada cultura, como na sociedade de caças de animais, ou mesmo nas primeiras sociedades agrícolas, onde a função reprodutiva pertencia somente às mulheres. Significa dizer que os primeiros papéis sociais atribuídos estavam relacionados ao órgão genital (determinação biológica) que o sujeito carregava em seu corpo - correlação exata entre sexo e gênero - e às funções que se esperava que desempenhassem naquela sociedade. A mulher, por exemplo, era a detentora da "criação", e as primeiras religiões surgiram sustentando essa lógica, como as religiões gregas e romanas, que apontavam para a criação do mundo a partir de Deusas; propiciando a existência de um contexto em que a mulher era vista como centro criador e gerador da vida. 
Os papeis sociais estabelecidos perpetuam-se ao longo da história, refletindo tanto nas religiões em vigor na sociedade, como na própria história do mundo, em sua construção cultural, e, portanto, na consciência e na compreensão de homem em cada época. Para Fonseca (2005) a mudança de perspectiva começa a ocorrer principalmente quando se nota a capacidade reprodutiva dos homens, e que a partir daí, passa-se a compreender o lugar de homem como aquele que possibilita essa criação, como um detentor dos meios de produção, inclusive, da vida.

A seguida, vemos esse movimento refletido nas mitologias de cada época, como quando a sociedade começa a retratar o homem como Deus, masculino, supremo, e que cria o mundo sozinho a partir de seu poder; compreendendo isso claramente a partir das religiões judaicas e cristãs que surgem nesse segundo milênio. Havia mitos que sustentavam o pensar das sociedades refletido na cultura do que é feminino - as mulheres eram secundárias e criadas a partir do homem - e ocorria a subordinação de tudo que era considerado como tal. Os homens eram os detentores do poder, o que incorria num papel social de dominância do que era propriamente considerado masculino nessas sociedades.

Historicamente, aquilo o que era definido como papel estabelecido para homens ou para mulheres, foi sendo modificado, a partir de um movimento de busca de igualdade entre os dois sexos. As mulheres, antes correspondiam às normas, obedeciam a padrões de feminilidade e sexualidade, passaram a esboçar seus próprios marcadores sociais e estéticos, como roupas e modos de integrar o meio social. Os homens dentro dessa analogia, eram identificados como o resto - tudo aquilo que não era considerado feminino e automaticamente era visto como uma característica masculino (Pinafi et al., 2011).

O lugar ocupado pelas instituições, como a religião, a educação, a família, serve de base para a constituição dos modos de pensar das sociedades, incluindo as primeiras noções de gênero, e as demais percepções sobre o que é feminino ou masculino. Os movimentos sociais denunciam, reprimem ou apresentam outras possibilidades para os corpos e as posturas de homens e mulheres, e passam a tomar o sexo feminino não mais como aquele detentor apenas de feminilidade e submissão; e o sexo masculino não somente como atrelado aos meios de produção, ou detentores de poder; mas permitem a expressão dos sexos e suas simbolizações de gênero, de modo distinto das estigmatizações primeiras, incentivando na busca pelos direitos frente à diversidade de papeis sociais existentes (Cruz \& Pedrosa, 2016).

\section{Subvertendo gênero: para além das noções binárias, representações sociais e modos de identificação}

Não se trata de negar o feminino e o masculino, mas de confrontar o que é compreendido dentro de cada possibilidade de gênero. Passando a compreender que os gêneros não se apresentam como uma categoria fechada, determinante, ou decisiva, e sim que sua diversidade passeia por mais diversos lugares e papeis sociais. As violências de gênero existentes revelam-se quando se busca a restrição dos lugares de expressão e modos compreensão de si no que diz respeito a um único modelo padronizado de gênero, de performance, e de corpo definitivo e imutável.

Butler (2013) aponta para a identificação que os sujeitos terão com os gêneros impostos socialmente como únicos, em uma relação binária e por vezes regularizadora e institucional, que por vezes não condiz com as possibilidades de experiência e traços diversos de gênero apresentados de maneiras distintas dentro de cada construção social, histórica e cultural em que se vive. Trata-se de uma visão do corpo como aquele que está no mundo, e que é construído por ele e através dele, numa troca do que é apresentado à experiência juntamente com o que aquele sujeito vivencia e simboliza. Isto direciona para uma nova lógica de compreensão de gênero, como aquele que é construído e descontruído constantemente ao longo do tempo e a partir das mudanças de cada era.

A dualidade sustentada e imposta pelas instituições sociais como feminino ou masculino, como coloca Pinafi et al. (2011, p.273) apresenta para nós que o modelo não binário:

[...] não só recusa o entre como também é resistente a pensar que o polo negativo desse modelo possa ter sua valência alterada em qualquer situação. Aceitar de pronto o binarismo homem/mulher remete a aceitar sem questionar a sexualização discursiva dos corpos pelas tecnologias e instituições. 
Diante disso podemos compreender o conceito de gênero e identidade como aquele que vai muito além das diferenciações anatômicas do sexo em si, anteriormente propostas. Pensar em gênero significa levar em conta construções de identificações diferentes que questionam a prioridade de qualquer atribuição de gênero supostamente fixa no sexo biológico, compreendendo a história e cultura embutidas nessas construções.

Compreende-se que o sexo constitui um determinante biológico e que o gênero, rompendo com representação homem/mulher, vai muito além de uma identificação do sujeito (ou não) com a sua natureza sexual. Como Butler, (2013, p.26) afirma: "Supondo por um momento a estabilidade do sexo binário, não decorre daí que a construção de homens se aplique exclusivamente a corpos masculinos, o que o termo mulheres interprete somente corpos femininos". O corpo, nessa concepção, torna-se variante.

O corpo vai apresentando-se como discurso. E o gênero não diz respeito apenas uma concepção advinda a partir da cultura (sendo a sua consequência), mas permeia os demais âmbitos de produção social e histórica, sendo concebido na historicidade concreta dos sujeitos. Sobre isso, Butler (2013, p.27) apresenta gênero na transgressão das concepções binárias:

Se o sexo é, ele próprio, uma categoria tomada em seu gênero, não faz sentido definir o gênero como a interpretação cultural do sexo. O gênero não deve ser meramente concebido como a inscrição cultural de significado num sexo previamente dado (uma concepção jurídica); tem de designar também o aparato mesmo de produção mediante o qual os próprios sexos são estabelecidos. Resulta daí que o gênero não está para a cultura como o sexo para a natureza; ele também é meio discursivo/cultural pelo qual "a natureza sexuada" ou "um sexo natural"

é produzido e estabelecido como "pré-discursivo", anterior à cultura, uma superfície politicamente neutra sobre a qual age a cultura.

Assim, torna-se viável a análise das formas de funcionamento do corpo como performance e identificação que propõe um discurso de posicionamento divergente da binaridade masculino e feminino. Foucault (1988), em sua obra A vontade do saber, interroga as relações de saber/poder existentes dentro desses discursos produzidos pela cultura. A ordem de normatividade - de um lugar indicativo do que deve ser vivido pelo sujeito, e como deve ser vivido (no sexo dito por ele, os desejos e proibições; ou para nós, na própria binaridade) - diz do que o poder tem como ordem de funcionamento e controle do meio social, numa tentativa de dominação que se dá pela imposição do que seja certo ou errado no campo da sexualidade e do corpo dos sujeitos.

O poder do instituído acaba por forjar grande parte do discurso sobre a sexualidade. Não se restringindo ao ato sexual em si, mas a qualquer prática que reporte a este campo (identidades, orientações, desejos, pensamentos, narrativas, funções e papeis). Desde os gêneros, até as formas de se relacionar com os outros, a forma como os sujeitos se comportam, e reproduzem a sua sexualidade, em ato, desejo ou vontade. A sexualidade comporta os seguimentos individuais e uma ordem institucional, pois é pelo discurso do próprio sujeito que as instituições dominantes fazem esse entrelaçamento entre poder e controle (Foucault, 2009).

E é em torno desse propósito que podemos compreender o agrupamento dos demais discursos presentes no meio, e na implicação que ele terá na construção do sujeito como tal, em suas identificações dentro do gênero e na compreensão desse dispositivo. Dispositivos definindo-se como demais linhas de tensão que atravessam o sujeito e o colocam nesse lugar do que ele é, e naquilo que ele se torna diante do que está posto socialmente (Foucault, 2009).

Diante disso, passamos a entender as verdades produzidas por essas instituições reguladoras como geradores de identidades de gênero que sejam condizentes com as normas existentes. Corroborando com Butler (2013, p. 44):

A matriz cultural por meio da qual a identidade de gênero se torna inteligível exige que certos tipos de "identidade" não possam "existir" - isto é, aqueles em que o gênero não decorre do sexo e aqueles em que as práticas do desejo não "decorrem" nem do "sexo" nem do "gênero".

Burlar essa lógica significa dispor-se a ir contra os diversos discursos de poder, e se deparar com a possibilidade de ausência de identificação, na busca por uma espécie de representatividade que não se encontra no atual referencial de produção de discursos, concepções e práticas ordinárias de vivência de gênero. Principalmente quando a única noção de representatividade (ansiada pelos sujeitos) revela-se como 
um exercício de encaixe ou adequação - de encontrar um lugar, ou um discurso, que reconheça e ofereça um espaço de pertencimento aos grupos e sujeitos de gêneros não convencionais. Tal movimento contrário, constituído pelo questionamento irrecusável da norma, desvela-se nas concepções foucaultianas relacionadas às as noções de Saber e Poder:

Com um funcionamento que é em parte diferente, as "sociedades de discurso" têm por função conservar ou produzir discursos, mas isso para os fazer circular num

espaço fechado, e para os distribuir segundo regras estritas, sem que os detentores do discurso sejam lesados com essa distribuição (Foucault, 2009, p. 11).

A própria procura por um lugar de gênero dentro dessa noção de dispositivo de controle coloca tal construção de verdade na esfera dos discursos sociais produzidos pelas instituições, a partir do momento em que confirmam ou negam esse posicionamento discursivo de um gênero não binário. Ao elucidar as relações de poder estabelecidas, Foucault fundamenta também as tecnologias de poder e suas lógicas de aprisionamento que cerceiam o sujeito ao necessário encontro de um lugar identitário de reconhecimento.

O não binário coloca-se como uma identificação que se constitui à margem do sistema em vigor. Gênero compreendido fora desse modelo binário seria a invenção de um discurso que se localiza na descontinuidade da identificação que anteriormente era necessariamente contínua e verdadeira, determinante e única. Como considera a autora Judith Butler (2013, p. 44): "A noção de que pode haver uma "verdade" do sexo, como Foucault a denomina ironicamente, é produzida precisamente pelas práticas reguladoras que geram identidades coerentes por via de uma matriz de normas de gênero coerentes [...]".

A não-binaridade de gênero configura-se como a possibilidade de um processo de identificação que não ocorre diante do masculino nem do feminino, podendo se dar tanto na fusão de ambos os gêneros, como também na negação de proximidade com quaisquer destes (não identificação), passando a ser entendido como algo fluido ou múltiplo, dependendo do modo como os discursos desses sujeitos se colocam em articulação aos seus posicionamentos e vivências.

A Psicologia Social Crítica aponta-nos a construção social do homem como sujeito no mundo, que se constrói a partir de sua história e cultura, no processo de subjetivação, oferecendo ferramentas para a sua compreensão frente a essa (não) correspondência com questões identitárias, inclusive, de gênero. Como nos esclarece Lane (1989, p. 12) sobre o homem que:

[...] fala, pensa, aprende e ensina, transforma a natureza; o homem é cultura, é história. Este homem biológico não sobrevive por si e nem é uma espécie que se reproduz tal e qual, com variações decorrentes de clima, alimentação, etc. O seu organismo é uma infra-estrutura que permite o desenvolvimento de uma superestrutura que é social e, portanto, histórica.

Ou seja, o homem existe no mundo e é constituído por ele, sendo inventor de sua existência. Ele constitui um produto do meio, sendo também produtor de novas demandas a partir de suas interações. Nessa concepção, a ideia de gênero foi forjada historicamente numa lógica binária de identificação. E, noutro contexto histórico e cultural, esta racionalidade de descontrói e se transforma diante de novas interações e possibilidades de se afirmar e reconhecer-se a si. No pensamento de Sílvia Lane (1989) o sujeito se constitui como algo indissociável das construções e processos de seu meio, considerando-se a noção de linguagem e de construções de fala como posicionamentos discursivos, os quais são entendidos como conteúdos repletos de significações e identificações do sujeito em confronto com o que está instituído, levando-o à diferenciação. Nas palavras da autora, torna-se preciso questionar a verdade dos discursos, e "compreender que representações sociais implica então conhecer não só o discurso mais amplo, mas a situação que define o indivíduo que as produz" (Lane, 1989, p. 37).

Numa compreensão das diversidades contemporâneas de gênero, em que se transbordam posições e papeis, as formas de entendimento da sexualidade e seus desdobramentos sociais são postas em xeque, recriando-se na ruptura com a lógica da binaridade de gênero. O processo de identificação produzido por essas instituições e suas racionalidades (lugares de saber) confronta-se com o poder que elas detêm sob o sujeito que busca a afirmação e o reconhecimento de si, propiciando ao mesmo tempo o espaço de não identificação com as normas estabelecidas, às quais se contrapõem os sujeitos não-binários constituintes desta investigação. 


\section{Considerações metodológicas}

\section{Delineamento metodológico}

A presente pesquisa se configura como qualitativa e exploratória (Marconi \& Lakatos, 2007) e tem como objetivo compreender o conteúdo disposto em discursos produzidos por dispositivos midiáticos - como blogs - sobre a identificação da não-binaridade de gênero, buscando-se assim fazer uma análise crítica desses discursos, em interface ao contexto social, histórico e cultural implicados.

A pesquisa foi realizada em blogs disponíveis na internet, que falam sobre o ser não binário no aspecto da identidade de gênero. Partindo da noção de que, como não há um acervo considerável de conteúdos científicos publicados sobre o assunto, essa escolha se daria pela produção de discursos sobre o tema, revelando dessa forma que tipo de sentidos e significados as pessoas têm acesso quando pesquisam sobre essa questão.

$\mathrm{Na}$ internet, os blogs se apresentam como domínios públicos de acesso, assim como sites e revistas, por se tratar de plataformas digitais de ampla criação e divulgação de informações no formato de mídia digital. Portanto, podemos analisar a questão ética desta pesquisa, em que blogs, por estarem inscritos nesse modelo de publicação, não precisou a análise do Comitê de Ética dado seu formato online e público.

Diante disso, é importante ressaltar também que os dados online aqui obtidos foram mantidos em seu formato original, sendo fiel ao material encontrado, recebendo os devidos direitos autorais por sua publicação e criação de conteúdo.

\section{Critérios de seleção dos dados}

Para determinar a amostra da pesquisa foi realizada uma busca avançada com o descritor: "O que é não-binaridade de gênero? - blogs" no Google', especificando o termo "blog" na plataforma de busca, para facilitar a geração de resultados mais específicos. Este levantamento ocorreu no período entre os meses de setembro e novembro de 2018, intervalo temporal em que os blogs encontrados estavam ativos e disponíveis na internet. A utilização da pergunta como pesquisa, foi escolhida para que ficasse claro que buscava blogs apenas com publicações que falassem diretamente sobre a definição desse lugar não binário. $O$ termo gênero também foi colocado para que não houvessem listadas outras discussões acerca da palavra binaridade além da pauta de gênero em si.

A partir dos resultados gerados automaticamente pela plataforma de busca, e como critérios de apuramento, escolheram-se apenas blogs brasileiros, que utilizassem a língua portuguesa, resultando em 89 links $^{2}$. A partir disso, buscou-se analisar apenas os endereços que apareceram nas primeiras 5 páginas de resultados de relevância (links mais acessados) e correspondência (fazer menção à não-binaridade) , utilizando o critério de saturação dos dados resultou em um total de 50 links. Iniciou-se assim a exclusão de servidores de sites, organizações ou vinculadas a estas, anúncios, páginas contendo vídeos, imagens, e outros que surgiram acerca do tema, mas que não correspondiam a busca inicial de blogs, e assim ao nosso objetivo de pesquisa.

Dentre os resultados devidamente inscritos em plataforma Google de formato de blog, como o Blogspot e Wordpress, foram encontrados 12 resultados de postagens publicadas derivadas de 11 domínios públicos diferentes. Desses, iniciou-se a exclusão de blogs que contivessem postagens que fugiam do tema pesquisado, priorizando páginas que contivessem a pergunta feita na pesquisa ou que tentassem responder a esta diretamente. Foram excluídos, também, blogs que tivessem conteúdos copiados de outras fontes, e aqueles que faziam parte de organizações, que não se caracterizam ao formato de blog pessoal escolhido - dando assim preferência àqueles que disponibilizassem textos autorais.

\footnotetext{
${ }^{1}$ Google é uma plataforma online utilizada como ferramenta de pesquisa e busca por informações em páginas disponíveis na internet.

${ }^{2}$ Links ou Hiperlinks significam hiperligações, são endereços eletrônicos de redirecionamento.
} 


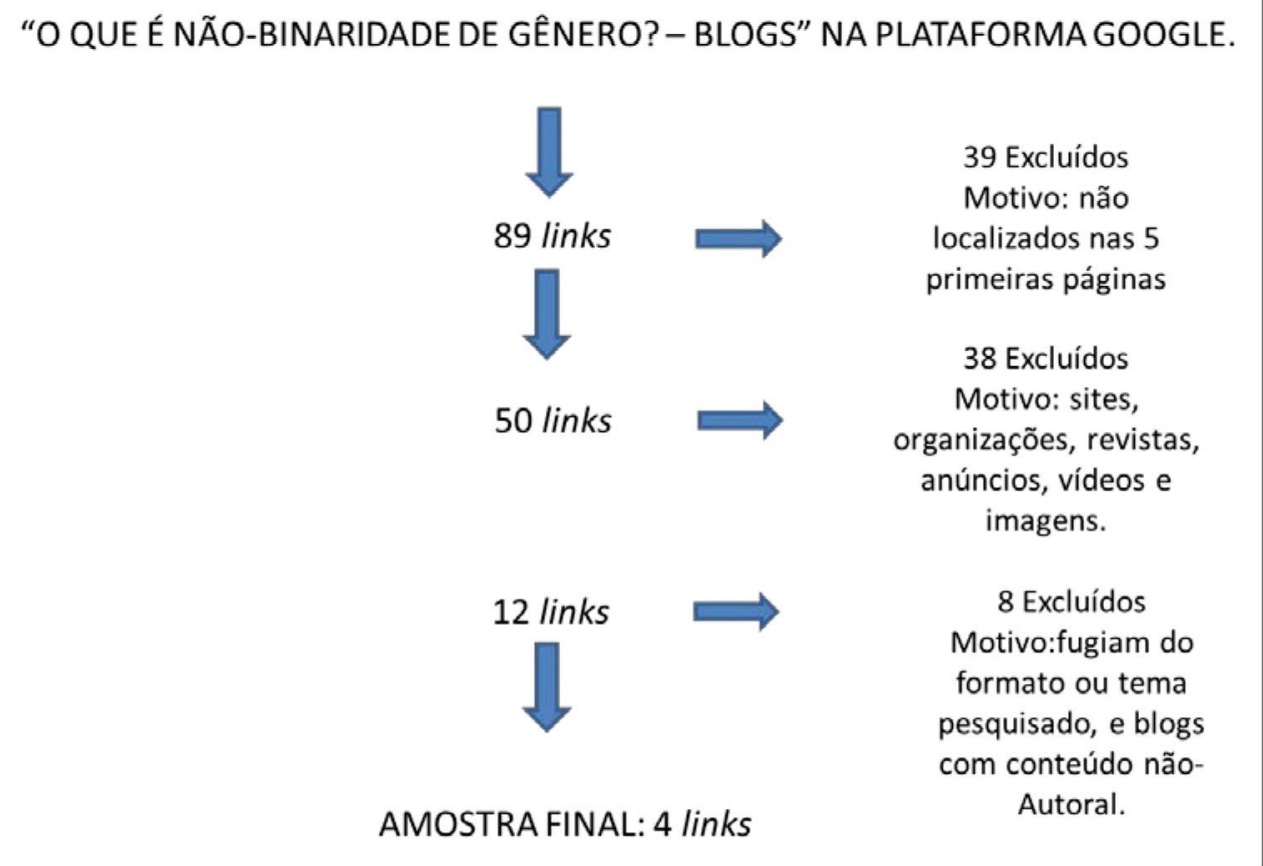

Os resultados foram: Felicia's Gaming Diary (https://feliciagamingdiary.wordpress.com/2018/02/28/representando-a-expressao-nao-binaria/), Breno Rosostolato http://brenorosostolato.blogspot.com/2015/05/nao-binarismo. html), Lohanna Pausini (https://pausini.wordpress.com/2018/08/13/as-incongruencias-da-identidade-de-generonao-binaria/), e Garoto Não Binário (https://garotonaobinario.wordpress.com/2016/04/03/ser-nao-binario/).

\section{Procedimentos de análise dos dados}

No que se refere à análise de dados, optou-se pelo procedimento da Análise Temática de Conteúdo (Bardin, 1977/1979). Esta consistiu na leitura dos discursos e o estabelecimento de aspectos comuns e diferentes entre os discursos expostos nos blogs e, finalmente, na construção de duas categorias temáticas.

O tratamento de dados se deu através do aporte teórico da Psicologia Social Crítica, que se apresenta como um modelo de interrogações ético e políticas sobre o meio social e suas relações com o sujeito, principalmente dentro da construção de novos saberes, e as produções que surgem a partir disso, numa percepção da construção de discursos, e o que eles carregam entre o dito e o velado em seus posicionamentos (Lima \& Júnior, 2014).

\section{Resultados e discussão}

\section{Significados não-binários de gênero: construções quanto aos termos descritivo e identitário}

Essa categoria expõe a percepção inicial de linguagem do termo não binário e de que formas ele se constrói dentro e fora dessa identificação de gênero. Tanto de maneira descritiva em seus significados como palavra, quanto de maneira identitária quando pensada através das colocações de gênero, aliando com a construção histórica, social e cultural de gênero. Na segunda categoria será discutido o lugar discursivo que essas falas envolvem, dentro de (não) definições, colocações e contradições, que buscam compreender os aspectos da não-binaridade dentro da performatividade. 
A análise se inicia a partir de uma compreensão do termo em sua forma descritiva, nos significados da expressão não-binaridade como palavra em si, e os conceitos que carrega. Em seguida, faz-se uma busca de suas definições, dentro de seu termo, quanto a forma de identidade de gênero e modelo de identificação atual, fazendo uma construção com seus conteúdos apurados.

Quanto termo descritivo, a noção de não binário vai nos remeter ao processo de construção histórica da própria consolidação social e cultural do que seria feminino ou masculino, numa compreensão das expressões que o gênero se utilizaria anteriormente para se identificar como um ou outro. Fonseca (2005) afirma que se trata de reconhecer os mecanismos do que definia a mulher como mulher, e o homem como homem, numa dissociação a partir dos sexos.

Ou seja, o binário, como o próprio termo em si já expõe, seria uma duplicidade, uma dualidade que não permitiria um sentido ternário de definição. Em contrapartida, a negação dessa binaridade abre um espaço de negação daquilo que é um ou outro apenas, numa negação dessa identificação por meio de genitais.

Nos blogs encontrados, a forma que o termo é descrito torna-se apropriado para esses discursos com esse teor de fuga, de não-junção:

Existem pessoas que não se encaixam à esta binaridade de gênero, masculino/feminino. Não se reconhecem exclusivamente homem/hombridade nem mulher/mulheridade. Possuem características individuais que se afastam do enquadramento exclusividade/totalmente sempre dos gêneros (Breno Rosostolato, 2015).

A partir do exposto pela postagem, podemos entender que se trata de uma não-identificação daquilo que é unicamente masculino ou unicamente feminino, que pode ser compreendido dentro de uma expressão de corpo que sai dos gêneros existentes e se coloca como fora desses padrões anteriormente estabelecidos.
Em Foucault (2009), compreendemos esse processo como uma negação daquilo que estava posto como uma "verdade" única, ou seja, confrontando o que era apresentando como uma categoria fechada, para uma análise social de expressão de corpo, a partir do termo em si, que retrata inclusive o movimento histórico e cultural atual da sociedade, que aponta os problemas de gênero dessa identificação dentro do sistema binário.

É interessante analisar partir dessa fala que nega essa díade homem/hombridade e mulher/mulheridade, como entramos em contato inclusive com uma crítica a um modelo de mulher que carregaria as categorizações sociais do que é imposto a esse papel feminino, e ao homem o papel masculino. É uma recusa que Butler (2013) remete a sua concepção de que o gênero não deve e não consegue estar enquadrado dentro da natureza dos sexos biológicos, mas sim, que se constrói de maneira discursiva, e que aponta para o modelo de funcionamento da sociedade dentro de cada cultura determinada.

Não se reconhecer nessa dualidade apresentada pela fala citada no blog, produz um questionamento sobre esse termo (binário) e de perceber que a expressão não-binária diz de tudo aquilo que foge dessas representações de papeis institucionalizados, de expressão de gênero e lugar de corpo. Pois, como sugere Butler (2013, p. 26): “Levada a seu limite lógico, a distinção sexo/gênero sugere uma descontinuidade radical entre corpos sexuados e gêneros culturalmente construídos."

Apresenta-se a nós, dentro dos discursos encontrados, uma distinção entre o sexo biológico e o gênero ao qual se pode identificar, numa negação do termo descritivo binário, e num questionamento das normas:

A concepção binária de que existem homens e mulheres não existe, definitivamente. A ideia homem/mulher, bem como masculino/feminino é uma criação social e que escraviza o corpo, porque o corpo muitas vezes não corresponde à identidade de fato da pessoa (Breno Rosostolato, 2015). 
Podemos pensar aqui também o lugar de fala que esse discurso se remete, em que ele nega a compreensão de gênero dentro de uma compreensão de binaridade. Ou seja: não existe homem e mulher? Ou não existe só essa compreensão? Que experiências históricas e sociais propiciaram essa construção discursiva ao sujeito que o permite pensar em gênero nessa quebra? Simboliza de certa forma, uma visão de não conformidade, de que homens em papeis de homens, e mulheres em papeis de mulheres são aspectos normativos, mas não existem de fato como categorias identitárias?

O apelo discursivo da expressão que o blog se utiliza - "escraviza o corpo", nos remete ao olhar de uma vivência que não é suportável, que normatiza de maneira obrigatória, impositiva, rígida e categórica. Dando espaço aqui para pensar as colocações de seu termo a partir das identificações identitárias de gênero:

[...] a identidade de gênero não tem nenhuma relação com o sexo biológico e nem com sua orientação sexual, á a forma como você se vê e se identifica, é algo que diz respeito a você e como você é no mundo (Garoto não binário, 2016).

Tais discursos nos coloca no lugar de compreensão das identificações já existentes que não entram na lógica homem e mulher, mas existem como outro-gênero. Ou seja, percebe-se a partir da leitura dos blogs que há uma diferenciação entre esse lugar colocado historicamente como papeis masculinos e femininos, distanciando do sexo biológico, resultando numa não-binaridade como termo dentro de um modelo de expressão de gênero, para uma diferenciação dos sexos, de uma disparidade do que é homem/mulher, se tratando de uma correspondência do termo com a própria identificação de gênero na transgeneridade (transexualidade).

Desse modo, compreendemos que a não-binaridade se trata também de um termo que carrega discursivamente nas falas apresentadas pelos blogs um teor de construção de identidade de gênero. Sendo assim, como em sua utilização na forma de termo de expressão de gênero, uma negação da dualidade apresentada no sistema binário. É a partir das percepções geradas por essas colocações que vamos buscar compreender as construções de gênero e seus sentidos e significados encontrados.

\section{Ser "não-binário": buscando definição para uma indefinição?}

Dentro das noções de gênero e identidade, aqui apresentadas, esboçamos uma discussão que busca compreender o lugar de fala desses sujeitos, e o que elas carregam, procurando compreender as formas de expressões de gênero que perpassam a não-binaridade, principalmente as construções sociais performáticas dessa identificação, e dos sentidos e significados que elas compõem.

Trazemos a ideia de "corpo como performance" (Butler, 2013), como aquele em que o sujeito, identificado (ou não) com algum dos gêneros dispostos, vai encontrar formas de se expressar subjetivamente para o outro e para o meio social, carregando consigo significações históricas e culturais, como se apresenta nessa primeira fala dessa categoria de análise:

Existem vários símbolos para identificar os gêneros masculino e feminino. E esses símbolos podem ser biológicos - como seios -, ou comportamentais - como as roupas que você usa. E esses símbolos são simples de se identificar. Todos nós fomos criadas cercadas por eles o tempo todo, e temos noções bastante sólidas

(talvez até sólidas demais) sobre o que é feminino ou masculino! (Felicia's Gaming Diary, 2018).

Quando pensamos no corpo como performance, podemos compreender nesse discurso do blog apresentado, o retrato de como essas performances podem existir e se pronunciar em cada sujeito. Compreendemos os símbolos sociais como aquilo que associamos ao feminino ou masculino, desde uma construção histórica e social. Em objetos, expressões, modos de se vestir, se comportar, e de se fazer falar através do que é apenas visualizado pelo outro, pela imagem, num corpo que apresenta quem é, através do que é compreendido pelo meio.

No próximo discurso pode-se estabelecer relações entre a fala anterior, que se constroem em torno do mesmo processo de reconhecimento da não-binaridade:

Eu sou não binário, não me sinto parte da divisão binária de homem e mulher que também nos é imposta. Desde que descobrem nosso sexo, já nos dividem em azul e rosa, carrinhos e bonecas, ação ou cuidados, e tantos outro. Sou algo entre esses dois gêneros, como uma sobreposição dos dois (Garoto Não Binário, 2016). 
De acordo com a literatura investigada, portanto, saímos dessa identificação de gênero socialmente apresentada a nós, quando nascemos, e construímos a partir dela, nossas primeiras associações para a nossa compreensão identitária. Ciampa (1989) nos apresenta, à luz da Psicologia Social, que outros questionamentos surgem dentro do simples questionamento de quem se é, e de como se constrói a identidade de cada sujeito.

Para o autor, a forma como compreendemos nossa identidade se apresenta como um discurso, uma fala construída a partir do que entendemos que poderia definir uma identidade, e ao mesmo tempo, quem somos individualmente, uma personagem frente a história por trás do que filtra de sua construção social. Aqui, mesmo quando a fala do blog nega as imposições duplas e abraça "o entre", ou como é colocado, a sobreposição, ele aponta o que oportunizou em si a criação e identificação desse discurso atual - ou seja, a própria divisão binária.

Você se pergunta "como pessoas não-binárias se parecem?" e TUDO que passa pela sua cabeça como possível símbolo visual de gênero pertence ou ao gênero feminino ou ao gênero masculino. E você simplesmente não consegue encontrar meios termos! Muito menos termos neutros! (Felicia's Gaming Diary, 2018).

Essa crítica tão cercada de definições de identidade que fogem de definições binárias, cria uma apresentação da identidade estranha ao reconhecimento comum social do que seria gênero (binário). No meio, são unidades vistas como estranhas, como definições de algo que ainda está indefinido, principalmente nas performatividades, no corpo, nas expressões que costumam definir ao outro, categorias e conexões de compreensão do que é experenciado, visto e vivido.

Mas existem formas de se expressar em uma neutralidade absoluta estando inserido no meio? De que forma de neutralidade se fala? Existem formas sociais que oportunizam ser múltiplo e ser reconhecido como tal, como os discursos dos blogs ensejam? São aspectos que se apresentam para nós como questionamentos desses espaços discursivos de uma compreensão não-binária, em que temos várias vertentes de posicionamentos. Uma delas seria de um reconhecimento do não-binário, como categoria, dentro das identificações sociais já impostas, apresentando o homem, a mulher, e a quebra ou continuação através de ambas as identificações, como já fomos apresentados.

Outra vertente seria a de um posicionamento que busca a multiplicidade/neutralidade de todas as identificações, em que não haveria necessariamente um lugar não binário, um de homem, e outro de muIher; e sim uma abertura ampla de reconhecimento no social que quebra qualquer dualidade de diferenciação. Essa posição falaria muito mais de uma descontinuação, de uma negação de construções sociais e de um posicionamento sempre pertencente a um não-lugar, a uma colocação de gênero - e não só o corpo - como performance.

Portanto, diante de tantas formas de se enunciar frente a um posicionamento social, compreendemos o que a performance de corpo apresentada por Butler (2013) e a construção de uma identidade no meio social elucidada por Ciampa (1989) nos mostra, de que esse lugar de posicionamento não-binário falará muito mais do sujeito que compõe esse discurso, e a forma que o compõe, do que as designações que o tentam compreender.

\section{Considerações finais}

Nesse trabalho, a partir de uma reconstrução histórica do que se compreendia pelo modelo binário de funcionamento, buscou-se abordar os formatos que o termo gênero tomou ao longo de nossa construção social, e dos lugares de corpo como performance e expressão, que foram sendo concebidos e percebidos nos modos de ser dos sujeitos no meio cultural contemporâneo.

Perpassamos os conceitos de masculino e feminino dentro e fora da dualidade homem e mulher, repensando esses papeis tidos como definitivos e determinados, buscando definir a não-binaridade como forma de (não) identificação de gênero, e questionando a própria construção social do que representa essa (não) identidade de gênero, a qual ocupa um lugar político importante num contexto de grandes mudanças. 
Adentramos as produções discursivas de blogs pautados tanto nas falas de construção de gênero orientadas por Judith Butler (2013), como também com um posicionamento crítico de Foucault $(1988 ; 2009)$ frente às dimensões do poder como político e mantenedor das instituições sociais através da compreensão da noção de dispositivo e de controle social.

Pautados na abordagem de interpretação dos dados na perspectiva da Psicologia Social Crítica, apresentada em Sílvia Lane (1989) e Ciampa (1989), pudemos conceber as formas de existência dos sujeitos no meio, os quais se posicionam como construtores da própria identidade, perpassados pelas influências sociais, culturais, e históricas de exclusão, de necessidade de pertencimento, e de lugares de fala e de expressão.

De tal modo, pudemos alcançar os objetivos desta investigação de apreender o lugar não binário de identidade de gênero a partir de mídias digitais (blogs), que se puderam analisar nos discursos dos sujeitos. Estes nos levaram à categorias que versaram sobre a não-binaridade como forma de subversão do conceito de gênero, e a compreensão dos termos e definições relacionados a essa experiência não binária de expressão de gêneros diversos e indefinidos.

Por se tratar de um tema pouco explorado, dada a carência de produções científicas, a pesquisa abre espaço para que novas noções sejam criadas, inclusive na desconstrução daquilo que permeia como masculino ou feminino em nossa sociedade, permitindo desmistificações, e novas construções críticas de posicionamento a partir de leituras inéditas sobre o tema.

Por fim, apesar de sermos apresentados a sua compreensão como termo descritivo e identitário, e como lugar de identificação na análise dos discursos dos blogs, a não-binaridade de gênero ainda se coloca como uma questão repleta de posicionamentos controversos, expressando-se como falas elucidativas de múltiplas possibilidades, abrindo espaço para discussões futuras. A questão, inferimos, trata-se muito mais do que uma simples forma de identificação, constituindo-se num indicativo da mudança contemporânea da racionalidade histórica de se pensar a categoria gênero. A investigação apresenta-nos um modelo obsoleto, que já não se comporta numa estrutura normativa, e assume o lugar ético-político de questionamento e posicionamento, e subverte os modos de olhar para o fenômeno e os modelos de funcionamento da sexualidade até pouco tempo exclusivamente em vigor em nossa sociedade.

\section{Contribuições dos autores}

Cardoso BML participou da concepção, delineamento, busca e análise dos dados da pesquisa, interpretação dos resultados e redação do artigo científico. Lemos PM participou da elaboração do projeto de pesquisa, no desenvolvimento metodológico, discussão e análise dos dados. Andrade AGS participou da redação do artigo, definição dos aspectos metodológicos, revisão geral.

\section{Conflitos de interesses}

Nenhum conflito financeiro, legal ou político envolvendo terceiros (governo, empresas e fundações privadas, etc.) foi declarado para nenhum aspecto do trabalho submetido (incluindo, mas não se limitando a subvenções e financiamentos, participação em conselho consultivo, desenho de estudo, preparação de manuscrito, análise estatística, etc.).

\section{Referências}

Butler, J. (2013). Problemas de gênero: Feminismo e subversão da identidade (13a ed.). Coleção Sujeito e História: Civilização Brasileira.

Ciampa, A. C. (1989). Identidade. In S. T. M. Lane, \& W. Codo (Orgs). Psicologia Social: O homem em movimento (8a ed., pp. 58-75). Brasiliense.

Cruz, A. L., \& Pedrosa, A. F. (2016, dezembro 23). Violência de gênero: Construções sociais e psíquicas. Revista Conversatio, 1(2), 484-496. http://docplayer.com. br/45215206-Violencia-de-genero-construcoes-sociais-epsiquicas.html

Felicia's gaming diary. (2018, outubro 17). Representando a expressão não binária. Felicia Gaming Diary. https:// feliciagamingdiary.wordpress.com/2018/02/28/ representando-a-expressao-nao-binaria/

Fonseca, R. M. G. S. (2005). A construção da identidade de mulheres e homens como processo histórico-social. Departamento de Enfermagem em Saúde Coletiva - USP, 1 , 1-12. https://edisciplinas.usp.br/pluginfile.php/185064/ mod_resource/content/1/identidade.pdf

Foucault, M. (2009). A Ordem do Discurso (19a ed.). Edições Loyola.

Foucault, M. (1988). História da sexualidade I: A vontade de saber. (13a ed.). Graal. 
Garoto não binário (2016). O que é ser não binário? https:// garotonaobinario.wordpress.com/2016/04/03/ser-naobinario/

Gerhardt, T. E., \& Silveira, D. T. (2009). Métodos de pesquisa (1a ed.) UFRGS Editora.

Giddens, A. (2002). Modernidade e identidade. Jorge Zahar.

Lane, S. T. M. (1989). A Psicologia Social e uma nova concepção do homem para a Psicologia. In S. T. M. Lane, \& W. Codo (Orgs). Psicologia Social: O homem em movimento (8a ed., pp. 10-19) Brasiliense.

Lane, S. T. M. (1989). Linguagem, pensamento e representações sociais. In S. T. M. Lane, W. Codo (Orgs). Psicologia Social: O homem em movimento (8a ed., pp 32-39). Brasiliense.

Lévy, P. (1996). O que é o virtual? Editora 34.

Marconi, M. A., \& Lakatos, E. M. (2007). Metodologia do trabalho científico. 7a ed. Atlas.
Pausini, L. (2018, outubro 27). As incongruências da Identidade de Gênero não Binária. Pausini. https://pausini.wordpress. com/2018/08/13/as-incongruencias-da-identidade-degenero-nao-binaria/

Pinafi, T., Toledo, L. G., Santos, C. H., \& Peres, W. S. (2011) Tecnologias de gênero e as lógicas de aprisionamento. Bagoas, (6), 267-282. https://www.cchla.ufrn.br/bagoas/ v05n06art11_pinafietal.pdf

Rosostolato, B. (2015, outubro 27). Não binarismo: feminino e masculino saem de cena. Breno Rosostolato. http:// brenorosostolato.blogspot.com/2015/05/nao-binarismo. html

Torrão Filho, A. (2005). Uma questão de gênero: Onde o masculino e o feminino se cruzam. Cadernos Pagu, (24), 127-152. https://doi.org/10.1590/S010483332005000100007 